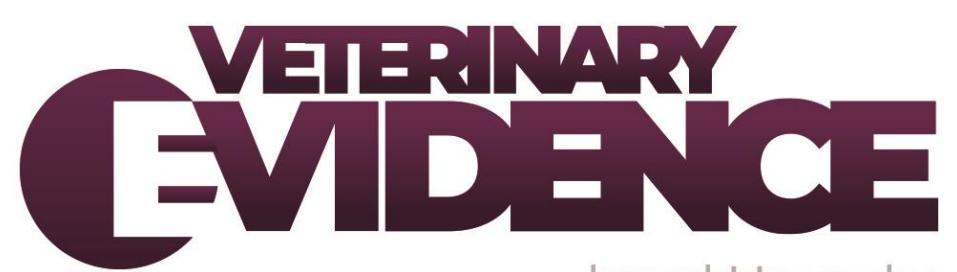

\title{
Pet owners' online information searches and the perceived effects on interactions and relationships with their veterinarians
}

Nanette Lai BSc BA MA ${ }^{1 *}$

Deep K. Khosa BSC BVMS MANZCVS PhD ${ }^{1}$

Andria Jones-Bitton DVM PhD ${ }^{1}$

Cate E. Dewey DVM MSc PhD ${ }^{1}$

\footnotetext{
1 University of Guelph, 50 Stone Road East, Guelph, ON N1G 2W1

* Corresponding Author (lain@uoguelph.ca)
}

ISSN: 2396-9776

Published: 08 Jan 2021

in: The Veterinary Evidence journal Vol 6, Issue 1

DOI: 10.18849/VE.V6I1.345

Reviewed by: Suzanne Rogers (BSc(Hons) CHBC) and David G. Thomas (PhD BSC) 
Objective: To explore pet owners' online search experiences for pet health information and the perceived effects on their interactions and relationships with veterinarians.

Background: Few studies have examined pet owners' online searches for pet health information; even less is known about how these search experiences may impact pet owners' interactions and relationships with veterinarians, including any effects on bond-centered care.

Methods: Qualitative study consisting of five focus groups conducted with 26 pet owners in the Greater Toronto Area, Ontario, Canada, between June to September 2016. All interviews were audio-recorded and transcribed verbatim. QSR NVivo $11^{\circledR}$ was used to facilitate organisation of focus group data for thematic analysis.

Results: Participating pet owners frequently referred to their relationships with veterinarians when discussing experiences searching online for pet health information. Owners reported choosing either to disclose or withhold declaring their online searches to veterinarians, depending on whether participants perceived a beneficial or detrimental impact on a "good" professional relationship with their veterinarian. Perceptions of veterinarians' reactions towards declaration of online searches were mixed, and influenced pet owners' views of the existing relationship.

Conclusion: Pet owners viewed their veterinarians as their most trusted source of pet health information, but many owners also wanted supplemental information from online searches. Owners preferred veterinarians refer them to online pet health resources, ideally those affiliated with the veterinary profession. Searching for pet health information online does not displace veterinarians' guidance. Rather, the veterinarian-owner relationship was perceived to be strengthened when online searches were openly discussed with veterinarians.

Implications: Findings offer insight into pet owners' expectations of veterinarians within the context of online pet health information, providing ideas for veterinarians to strengthen bonds with owners such as; showing support of owners' online pet health information searching by recommending resources and considerations about communicating professional opinions to owners regarding online information.

INTRODUCTION

An expanding body of literature documents research in relationship-centered healthcare which emphasises a collaborative healthcare model built on partnerships and joint decision-making between human healthcare providers, patients, and their families (1-4). Arising from studies in human medicine (5) and social sciences (6), such relationship-centered care $[R C C]$, acknowledges a growing need for equal participation in health decisionmaking. Awareness for RCC has also become a focus of increasing research in veterinary medicine (7), where this collaborative healthcare model has also been termed bond-centered care [BCC] or bond-centered practice $(8,9)$. BCC recognises the unique relationship and bond shared between a pet and its owners (8). In acknowledging the owner-pet bond, the veterinarian aims to understand the pet's healthcare needs whilst concurrently meeting and addressing the needs of the owner (9-11). It is recognised that this type of holistic approach supports the development of a collaborative relationship or bond between owners and veterinary service providers, facilitating joint healthcare decisions for the pet $(10,12)$.

The existing literature on BCC has largely focused on the veterinarian's role in the veterinarian-pet owner interaction. For example, publications describe $B C C^{\prime} s$ underlying philosophy to provide guidance for veterinarians on integrating this healthcare model into daily practice $(4,11)$, including some research that 
focused on the impact of practicing BCC on veterinarian wellness $(12,13)$. Other research emphasises the veterinarian's contributions to BCC, highlighting the veterinarian as an educator and support person along with being the medical expert to help pet owners in decision-making (14). Related publications offer ideas to veterinarians for enhancing their contributions in BCC, such as developing communication skills to build strong bonds with pet owners $(4,10)$. In contrast, far less research has investigated pet owners' contributions in BCC. The few publications focused on pet owner contributions in BCC demonstrate owners' desire to have increased involvement in choosing treatments and therapies for their animals $(10,15)$. To help with their participation and decision-making in their pets' healthcare, pet owners are known to search for pet health information across a variety of resources, such as newspapers or generic pet care books and associated literature (16). More recently, the Internet is recognised as a common and readily accessible resource that many owners report using for pet health information $(16,17)$. For example, Kogan et al. (2009) reported that nearly three-quarters of 1622 surveyed pet owners who were veterinary clients residing in or around two metropolitan areas in the United States (Knoxville, Tennessee and Denver, Colorado) had reported using the Internet to search for pet health information. Hofmeister et al. (2008) noted pet owners ranked the Internet as their third most commonly accessed pet health information resource, behind general practice and specialist veterinarians. More recently, Kogan et al. (2018) reported the Internet as being the most frequently cited source of pet health information (78.6\%), with veterinarians being a close second (77.2\%) from a survey of 571 pet owners in the United Kingdom.

The extent of research about pet owners' online pet health information seeking is particularly scant when compared to the extensive volumes of literature discussing online human health information seeking (21-29). Human medical research shows that online information seeking behaviour impacts patients' interactions and relationships with physicians. For example, human patients who found online information that contradicted their physicians' clinical interpretations actively mentioned their online searches during consultations with physicians (30). Other research shows patients avoided bringing up online health information searches during consultations with physicians to prevent damaging the professional relationship (31-33). It has also been reported that patients observed their physicians' behaviours during clinical encounters to guide decisions about whether to reveal their online health information searches (34).

In the veterinary context, pet health outcomes may be impacted by veterinarian-pet owner relationships and interactions, including the fact that owner decisions related to the use of veterinary services is influenced by the veterinary-client relationship (35-38). Little is known about how online pet health information seeking influences pet owners' interactions and relationships with veterinarians, factors involved in the veterinarianowner bond component of BCC (10). The goal of this study was to add to the limited understanding of pet owners' online pet health Internet information searches, and owners' perceived effects on veterinarian-owner interactions and relationships. The specific objectives were to explore; 1) pet owners' online resource preferences for seeking pet health information; and 2) how online search experiences influence veterinary interactions and relationships from the owner's perspective.

METHODS \& MATERIALS

\section{Study design and participants}

This exploratory qualitative study involved a series of five focus groups, comprised of individuals who identified themselves as current owners of at least one cat or one dog. Focus groups were conducted between June and September 2016 in the Greater Toronto Area, Ontario, Canada. Recruitment for participants began in June 2016 using diverse social media platforms (e.g. Facebook, Instagram, Twitter) and snowball recruitment (37). Pet owners were informed of the purpose and format of the study and were offered an honorarium (\$50 CAD gift card) and meal for participating.

Each focus group was run when three or more individuals had confirmed their availability to participate during specified dates. All participants were made aware of the risks, benefits and repercussions of their involvement 
in the study, and accordingly consented to their involvement before the start of each focus group discussion. The study protocol received ethics approval from the University of Guelph Research Board (REB \#016AP002).

\section{Data Collection}

At participants' convenience, focus group discussions took place at private homes and one was held at a community centre. A semi-structured question guide was used to discuss topics pertaining to participants' experiences searching online for pet health information, including: online resources they had accessed; methods participants used for evaluating quality and validity of online pet health information; experiences communicating with veterinarians regarding online pet health information; and participants' opinions about online pet health information. Questions were open ended and designed to stimulate discussion among the pet owners, facilitating the moderator (first author) to explore a range of perspectives and shared experiences. Data saturation was achieved by the fourth focus group discussion, where new information was not presented by participants (39). The fifth focus group was conducted to confirm data saturation.

All discussions were audio-recorded, transcribed verbatim, and de-identified to ensure that transcribed

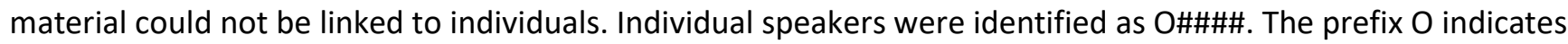
the speaker was an owner, and \#\#\#\# consists of a unique number assigned to the individual. Participants completed a short demographic questionnaire post-interview to collect data on gender and age in order to describe the study population. Validation techniques used to lend rigour to the study included field notes taken by the moderator to document observations and non-verbal behaviours with the use of thick, rich description (40).

\section{Data Analysis}

All transcripts were systematically checked for accuracy against the audio-recordings by the first author. The computer software QSR NVivo $11^{\circledR}$ was used to facilitate organisation of focus group data for thematic analysis (41). In brief, each transcript was examined multiple times for familiarisation with the data, and open codes were applied to sections of text. Common codes occurring across transcripts were merged into themes and sub-themes and described in a codebook. The themes were then systematically reviewed, named and defined. For consistency and clarity, naming and definition of themes and sub-themes were reviewed and cross checked with codes by the second author. Verbatim quotations are presented to illustrate codes. In some instances, "..." is used to denote where words were removed by authors for clarity; words included in square brackets were added by the authors for clarification purposes. Demographic data were analysed using descriptive statistics (e.g. means, median, proportions) using Microsoft Excel ${ }^{\circledast}$.

\section{RESULTS}

\section{Demographics}

Twenty-six pet owners participated in the five focus groups. Each focus group ranged from 3 to 9 participants (mean: 5) and ran from 46 to 78 minutes each (mean: 58 minutes). Pet owner ages ranged from 21 to 65 years old (mean: 40.8 years); 23 (88.5\%) identified as female, and $3(11.5 \%)$ as male.

Two major themes pertaining to the project objectives were identified in thematic analysis of the data. Both themes, and their associated sub-themes, are described below.

Theme 1: Owners viewed veterinarians as their most trusted source of pet health information and also wanted supplemental online pet health information

Owners across all focus groups acknowledged that veterinarians they had relationships with were irreplaceable as a source of trustworthy pet health information. However, many were also clear in wanting to augment that information by way of online pet health information searches that involved their veterinarian. The following three sub-themes describe this theme: 
Sub-theme 1.1: Owners wanted online information to augment information provided by their veterinarians, but veterinarian referrals to online pet health information were rare

While nearly all owners considered their veterinarians as their primary information resource for pet health information, they also searched online for supplemental information. For example, one owner stated that: “... being a university student I'm very picky about resources and I definitely go for vet first... I'll go to the vet first and then go online for follow-up." [00105] Similarly, other owners' online pet health information searches occurred as follow-ups to veterinary consults.

To further explore owners' experiences with veterinarian-recommended online pet health information resources, participants were asked about online content that veterinarians had referred them to. Nearly all participants reported that veterinarians rarely directed them towards online resources for retrieving pet health information, as demonstrated by one owner who stated: "I've never actually been recommended anything by the vet." [00523] Other participants appeared to have similar experiences with veterinarians not directing them to specific online resources. One owner reported that "I only get the "be careful of people believing they're vets because they've had pets for years' kind of caution, but not a specific recommendation." [00105] Similarly, one owner made the following contrast between veterinarians and physicians:

"I don't know if you guys experienced the same thing. But the vets never give us any sites to look up things... if you ask your doctor on something, they would give you something to reference. But vets never do that." [01037]

Another owner noted that she did not recall veterinarians referring her to a specific type of online resource: "I don't recall any vet directing me to a study. Would be nice." [00521] The participating pet owners' statements appear to indicate that some may have information needs they wish veterinarians to meet.

\section{Sub-theme 1.2: Owners wanted veterinarians to verify and check online information}

Owners described independently conducting online pet health information searches and wanting their veterinarians to verify the information they identified. For example, several owners explained that they would first go online for information, and then contact their veterinarians to verify accuracy of the content. This was depicted by multiple owners, such as one participant who explained: "I would link [the online source] to an email to my vet and say '... is this... true?"' [00314] Some owners opted to have verbal conversations with their veterinarians for the same purpose: "If I find something on the Internet that causes me concern I'll call them [my veterinarians] and run it by them." [00108] "I actually don't trust the Internet that greatly... I'd still bring the information to my vet." [01037] One owner expressed that information he encountered ultimately required his veterinarian's approval: "... If I found something online, and he [the veterinarian] said, 'no, that's totally wrong,' you know, I'll trust him... I'll disregard what I found on the Internet. In our case, the vet has the final say." [01040]

Sub-theme 1.3: Owners want veterinarians to recommend online information resources - ideally affiliated with the veterinary profession

Owners expressed a desire for their veterinarians to recommend online pet health resources that veterinarians themselves had appraised. One owner reported that her own veterinarian helped initiate the owner's search by giving her a web link to access after the consult: "Our puppy was diagnosed with one of the tick-borne diseases... the vet provided us a link to information... I copied and pasted the actual disease name. And just read up on... symptoms we should be looking for." [00314]

Several owners described wanting online resources that were created by the veterinary profession or that their veterinarian had contributed content to. For example, one owner expressed: "If I could find my veterinarian's name on the website... if he is willing to place his name on this website then yes, I will also trust this website." [01040] The latter idea was further emphasised by owners wanting to be directed to online pet health resources affiliated with professional veterinary associations, as explained by another participant: 
"I don't know if it's... possible or something, but if [there was] like a vet association driven, kind of FAQs... Those you know that the doctors contribute to it, they have their own studies to back it up... if there's... a centralised, accredited go-to site, or sites... That, I think that would be very helpful for pet owners." [01037]

This idea of having a veterinarian-authored online pet health information resource appeared to be shared by other participants. For example:

"For my own personal issues, I always go to the Mayo clinic. 'Cause I know they always have the top research. Best doctors. Everybody looks to the Mayo clinic for information. I'd love to see one for cats and dogs... [where] all the top vets are working together, putting their resources out there so that pet owners can actually go look at it and just go 'okay now I have a better understanding of my animal's disease' or condition and you know, a little checklist of all the things and what to look for." [00936]

Another participant elaborated on the idea of having an online pet health resource connected to a professional veterinary association, noting:

"For human health... you have... different sites... that you know are reputable and accurate. It's kind of hard to know with the pet sites... there's nothing that sticks out in my mind that... is the go-to site, that... their information would be accurate." [00317]

Theme 2: There was a relationship between owners' perceptions of their relationships with their veterinarians and disclosure of online searches for pet health information

The second theme identified in the analysis related to a relationship between owners' perceptions of the veterinarian-client relationship and the disclosure of owners' online searches for pet health information with their veterinarian. Specifically, how the owners' perceived the veterinarian-client relationship influenced whether they disclosed their online search information to their veterinarian (Sub-theme 2.1). Further, how veterinarians were perceived to respond to owners' online searches influenced the quality of the veterinarianclient relationship (Sub-theme 2.2). Each sub-theme is further described below.

\section{Sub-theme 2.1: Owners' perceptions of the quality of the veterinarian-owner relationship influenced owners} disclosing online searches

In discussing their most recent online pet health information searches, participants described how the perceived quality of the veterinarian-client relationship influenced their discussing online search results with veterinarians in multiple ways.

Some owners who depicted the relationships in a positive manner, such as describing their relationships with veterinarians as "good," reported sharing their online pet health information search results with their veterinarian. For example, one owner described how having a good relationship with veterinarians facilitated conversations about searching online for pet health information; "... when you're sifting through information and you have a good relationship with your vet... you can bring things up as discussion topics." [00523]. Other participants agreed, with one owner commenting that, "I have a really good relationship with my vet... they don't mind me bringing things [from the Internet] to them." [00104].

In contrast, other owners who also considered their relationships with their veterinarians as "good" voiced hesitation about sharing their online pet health information search activities with their veterinarian, as they would usually defer to their veterinarian's expertise regardless. For example; "I've got a really good relationship with my vets... at the end of the day... [I] defer to them and never really challenge them based on something I've read on the Internet... that'd be a little foolish." [00108] Another owner agreed, sharing her thoughts about why she preferred not telling her veterinarian about her online search results; "[the veterinarian is] good at what he does, and I've used him for all three dogs. They would rather I show up than... research on my own." [00936] These sentiments seemed to suggest a hesitancy amongst these owners about 
disclosing online searches with their veterinarian because they perceived it would not be well-received by the veterinarians.

Other participants were more clear in describing that they did not share online search information with their veterinarians because they believed doing so could harm the veterinarian-client relationship. For example, one owner explained that:

"... I've been working with him [veterinarian] for a long time and I... get the sense that he, some vets don't like when their clientele looking up things on the Internet... I try to... approach that lightly with my vet and not bombard him with information." [00315]

Another owner stated; "I think you have to be very diplomatic when you're giving information to your vet... it does depend on your relationship with your vet." [00102]. The same owner also shared the following thought;

"when you're seeing a new vet you... have to tread lightly. 'Cause I'm sure everybody's going on the Internet looking for stuff... they're just reading it off the Internet and then thinking that they know as much as the vet. Which I could see from the vet's point [of view] would be a little frustrating."

\section{Sub-theme 2.2: Veterinarians' reactions towards owners disclosing online searches impacted owners' perceptions of the relationship}

Multiple participants shared their experiences with presenting online pet health search findings to their veterinarians. The owners' perceptions of their veterinarians' reactions to this disclosure influenced the veterinarian-client relationship.

In some instances, owners perceived their veterinarian's reaction to being presented with online information as negative. For example; one owner recounted a past experience where she viewed the veterinarian as being unreceptive to her ideas, including her website recommendation;

"I referred [the veterinarian] to [a dog care website] to start doing a little bit of research because the movement is to get away from vaccinations. I dropped him as a vet because he was toeing the party line and wasn't willing to consider that [my] dog even had a reaction to the [rabies] vaccination." [00103]

Similarly, another participant reflected on a past attempt in sharing her online findings with a veterinarian; "I found... a university paper... I said 'I've got this paper can I email it to you' [the veterinarian said] 'I'm not giving you my email.'... he was openly hostile... so I went to a different vet... And we switched." [00109]

In these instances, the reaction of the veterinarian to the owner sharing their online search information was perceived so negatively such that it led to the owner terminating the veterinarian-client relationship.

In contrast, veterinarians' reactions that were perceived to be positive appeared to influence owners' constructive views of the professional relationship. This was well-demonstrated by one owner's comment regarding her pet that had chronic anal gland infections;

"... my vet was at the point of saying if he gets one more infection, we're removing them. I'm like that's a really risky surgery... if I don't have to knock him out, I don't want to... I did some independent research... studies had been going on for a couple of years... saying that any chronic dermalogical [sic] issue is usually food based. And my vet wasn't even aware that anal glands were considered part of the dermis... he was going to go to the extreme of taking them out... I had to take him all kinds of reports." [00525]

When asked to elaborate about the veterinarian's response the owner stated; 
"... he was actually awesome about it. I know other vets would not be, but he was always willing to learn new things and never make me feel uncomfortable about taking him things that contradicted what he'd said to me."

Similarly, other participants discussed sharing online search information with their veterinarian as helping to facilitate a stronger veterinarian-client relationship. For example;

"... it's about you finding information... and them being willing to listen... discuss things with you... more of a relationship... together." [00109]

"... at the end of the day, all that information... helps me to have a more intelligent conversation with my vet. I think it really helps to have a much deeper relationship with your... vet." [00108]

"... before all the information was on the Internet... you'd call and they [veterinarians] would say 'You gotta bring the cat in.'... now they're willing to discuss a bit more over the phone... I think it really helps you have a much deeper relationship with your vet." [00104]

Hence, owners' interpretations of veterinarians' reactions towards being presented with online pet health information affected how participants viewed the professional relationship. Where veterinarians were perceived to react well to the online information, relationships were strengthened, but where the veterinarian's response was perceived as negative, it harmed the veterinarian-client relationship.

DISCUSSION

This research aimed to explore pet owners' online searches for seeking pet health information, including how online search experiences influence veterinary interactions and relationships from the pet owner's perspective.

Consistent with previous research $(19,42)$, pet owners in the present study indicated that their preferred pet health information was that provided by veterinarians. At the same time, many owners wanted supplemental information from online searches, and expected veterinarians to provide guidance about online content. Our findings support past research indicating pet owners would welcome website suggestions from veterinarians (43), yet, as with the views from the participants in our research, pet owners generally do not receive website recommendations from veterinarians $(18,43)$. To the authors' knowledge, website recommendation behaviours and patterns among veterinarians have not been investigated. However, investigations from the human medical field may offer some insight. Similar to pet owners, human patients also have a predilection towards health information from healthcare providers rather than the Internet (44). Physicians have been reported to recommend websites to the patients who request them or when patients expressed that they used the Internet for seeking health information $(45,46)$. As a point of contrast, findings from the present research and one other pet owner related study (17) report that some pet owners tended to avoid mentioning Internet use to their veterinarians. Speculatively, pet owners not mentioning their Internet use to veterinarians may affect whether veterinarians recommend online resources. More research is warranted for exploring when and why pet owners are or are not referred to web-based pet health resources by veterinarians.

Some pet owners in this study expressed being reticent about discussing their online pet health information searches for fear of disrupting what they considered to be a "good" relationship with their veterinarian. Because previous research in veterinary medicine has not explored pet owners' perspectives about the impact of their Internet use on their relationships with veterinarians, literature from human medical studies have been cited here for comparison. Human patients have been reported choosing not to convey their online search activities to their physicians in order to maintain a good quality professional relationship (23). Other 
research indicates human patients perceive improvements in relationships with physicians from discussing online health information (48-50) when physicians' had positive responses towards patient Internet search efforts $(49,53)$. For example, human patients associated physicians' positive reactions with improved therapeutic relationships, whilst negative or dismissive reactions from physicians were considered damaging to the relationship $(50,54)$. The findings from the present study support both premises; that disclosure of online information searches are perceived to harm relationships with health professionals in instances where the health professional was perceived to respond negatively to the disclosure, but improve relationships where the health professional's response was perceived to be positive. Moreover, reports document physicians' negative reactions, such as being disparaging or acting threatened towards patients' Internet searches, may drive patients' deciding to discontinue the professional relationship (54), again akin to reports by some of the pet owners in this study.

The depth of research in human medicine offers further insights and directions for future research in veterinary medicine. Research reports that human patients viewed physicians' reactions to be positive when the physicians engaged with the Internet information, such as validating and encouraging patients' searches (54). Even if physicians actively disagreed with the Internet content or expressed a lack of knowledge, human patients viewed these as positive responses, much as was observed with the pet owners' views in our study. Moreover, and similar to the findings from the present study, human patients considered their physicians' reactions to be mostly positive if they had a good prior relationship (55). The effect of a positive existing relationship consistently influenced human patients' views even when the physicians were actually being critical (50). Furthermore, physicians criticising online health information was considered by patients to be a positive reaction because the physicians demonstrated engagement with the information. Inversely, human patients deemed physicians' reactions to be negative if the physicians appeared disengaged with the Internet materials, even if they agreed with the content (50). Physicians appearing to patients as being disengaged with Internet information was viewed as responding negatively by patients, and some opted to see other physicians or the patients left the practice entirely $(50,55)$. In light of responses by human patients, an avenue for future research may involve exploring pet owners' views about veterinarians' engagement with pet health information on the Internet. Specifically, the extent to which veterinarians engage in discussions about online information and the impact that discussions have on the veterinarian-pet owner interaction and relationship.

\section{Implications}

The present research suggests conversations between veterinarians and pet owners regarding online pet health information can positively impact the professional relationship, provided pet owners view veterinarians' reactions to the online information disclosure to be positive. Specifically, akin to human research, pet owners may consider veterinarians' reactions to be positive if the veterinarians demonstrate support of owners' online searches, such as veterinarians verbally acknowledging owners' information gathering efforts. Pet owners' perceptions of veterinarians' responses may be affected by veterinarians' communication skills (57). Drawing from suggestions for physicians (58), veterinarians demonstrating openness towards online health information may encourage pet owners to share their online pet health information research. Also, enabling owners to discuss online findings communicates that their opinions are valued, as seen with human patients (47), and further emphasises the equal participation in bond-centred care (8-10). Another benefit from open discussions about online health information includes potential strengthening of the veterinarian-owner relationship, as was observed here and is also depicted among human patient-physician relationships (47). Research links strong veterinarian-pet owner relationships to increased veterinary service use and owners following veterinary recommendations - factors which are associated with improved pet health outcomes (34) and veterinary business outcomes.

Practical applications for bond-centred care based on the present research focuses on strengthening the veterinarian-pet owner bond. Based on evidence from the literature, ideas for supporting positive veterinarian-owner interactions centred around owner Internet use include engaging with owners, such as verifying content together (59). Veterinarians may also consider directing owners to specific online resources as part of the veterinary consult (60). Related suggestions include veterinarians integrating Internet use into consultations with owners (61) or referring owners to external online resources for pet health information (57). 
Veterinarians can enhance their bonds with owners by providing strategies and educating owners about assessing websites for accuracy and reliability (17). Arming owners with the skills to recognise valid information from the Internet becomes even more important within the context of bond-centred veterinary care, given that existing research has demonstrated that health information online may be misleading and potentially influence health information seekers' attitudes towards diseases, medical treatments, or procedures (45).

\section{Limitations}

A limitation of this study is the potential for response bias since pet owners who agreed to be interviewed may be more comfortable sharing their experiences searching for online health information, and the challenges they had encountered during searches and wished to specifically voice this. As with all qualitative research, this study was not designed for establishing statistical generalisability; therefore, results cannot be generalised for all pet owners. Outcomes of this study provide depth of understanding in a previously under explored phenomenon and will be used to guide the development of a quantitative questionnaire for measuring the frequency and distribution of some of the observed phenomena in the broader Canadian pet owner population.

\section{Conclusions}

Pet owners viewed their veterinarians as their most trusted source of pet health information, but many owners also wanted supplemental information from online searches. Owners described wanting to veterinarian referrals to credible sources of online information, but these were rare. There was a relationship between pet owners' perceptions of their relationships with their veterinarians and how pet owners perceived their veterinarians' reactions to their disclosure of online pet health information searches. Searching for pet health information online does not displace veterinarians' guidance. Rather, veterinarians acknowledging, recognising and engaging in pet owners' Internet research efforts can serve to strengthen the veterinarianowner relationship.

\section{CONFLICT OF INTEREST}

Acknowledgements: Research costs were supported by the Ontario Veterinary College Pet Trust Fund. The authors thank all the pet owners who agreed to participate in the focus groups

Funding: Ontario Veterinary College Pet Trust Fund

Competing interests: The authors declare no conflicts of interest

\section{REFERENCES}

1. Hou, J. and Shim, M. (2010). The role of provider-patient communication and trust in online sources in internet use for health-related activities. Journal of Health Communication. 15(sup3), 186-99.

DOI: https://doi.org/10.1080\%2F10810730.2010.522691

2. Thompson, A. (2016). Hippocrates and the smart phone: the evolving parent and doctor relationship. Journal of Paediatrics and Child Health. 52(4), 366-9.

DOI: https://doi.org/10.1111/jpc.13170

3. Sevransky, J.E., Nicholl, B., Nicholl, J-B. and Buchman, T.G. (2017). Patient- and family-centered care. Critical Care Medicine. 45(5), 757-8. DOI: https://doi.org/10.1097\%2Fccm.0000000000002431 
4. Küper, A.M. and Merle, R. (2019). Being nice is not enough-exploring relationship-centered veterinary care with structural equation modeling. A quantitative study on German pet owners' perception. Front Veterinary Science. 6, 56. DOI: https://doi.org/10.3389/fvets.2019.00056

5. Suchman, A.L. (2006). A new theoretical foundation for relationship-centered care-Complex responsive processes of relating. Journal of General Internal Medicine. 21(S1), S40-4.

DOI: https://doi.org/10.1111\%2Fj.1525-1497.2006.00308.x

6. Charles, C., Gafni, A. and Whelan, T. (1999). Decision-making in the physician-patient encounter: revisiting the shared treatment decision-making model. Social Science and Medicine. 49(5), 651-61. DOI: https://doi.org/10.1016\%2Fs0277-9536\%2899\%2900145-8

7. Kanji, N., Coe, J.B., Adams, C.L. and Shaw, J.R. (2012). Effect of veterinarian-client-patient interactions on client adherence to dentistry and surgery recommendations in companion-animal practice. Journal of the American Veterinary Medical Association. 240(4), 427-36.

DOI: https://doi.org/10.2460\%2Fjavma.240.4.427

8. Pukay, B.P. (2000). The impact of the human/companion animal/veterinarian bond on the future of the veterinary profession. The Canadian Veterinary Journal. 41(1), 28-9.

9. Ormerod, E.J. (2008). Bond-centered veterinary practice: lessons for veterinary faculty and students. Journal of Veterinary Medical Education. 35(4), 545-52.

DOI: https://doi.org/10.3138\%2Fjvme.35.4.545

10. Rötzmeier-Keuper, J., Hendricks, (née Lerch) J., Wünderlich, N.V. and Schmitz, G. (2018). Triadic relationships in the context of services for animal companions. Journal of Business Research. 85, 295303. DOI: https://doi.org/10.1016/j.jbusres.2018.01.003

11. Coe, J.B., Adams, C.L. and Bonnett, B.N. (2007). A focus group study of veterinarians' and pet owners' perceptions of the monetary aspects of veterinary care. Journal of the American Veterinary Medical Association. 231(10),1510-18. DOI: https://doi.org/10.2460/javma.231.10.1510

12. Steiner, E.T. and Silver, N.C. (2013). Raising canine: cross-species parallels in parental investment. Human-Animal Interact Bull. 1(1), 38-54.

13. Stoewen, D.L., Coe, J.B., MacMartin, C., Stone, E.A. and Dewey, C.E. (2013). Factors influencing veterinarian referral to oncology specialists for treatment of dogs with lymphoma and osteosarcoma in Ontario, Canada. Journal of the American Veterinary Medical Association. 243(10), 1415-25. DOI: https://doi.org/10.2460/javma.243.10.1415

14. Shanan, A. (2011). A veterinarian's role in helping pet owners with decision making. Veterinary Clinics of North America: Small Animal Practice. 41(3), 635-46.

DOI: https://doi.org/10.1016/i.cvsm.2011.03.006

15. Tian, K., Sautter, P., Fisher, D., Fischbach, S., Luna-Nevarez, C., Boberg, K., Kroger, J. and Vann, R. (2014). Transforming health care: empowering therapeutic communities through technologyenhanced narratives. Journal of Consumer Research. 41(2), 237-60.

DOI: https://doi.org/10.1086/676311

16. Murphy, S.A. (2006). Consumer health information for pet owners. 94(2),152-8.

17. Kogan, L., Schoenfeld-Tacher, R., Simon, A. and Viera, A. (2009). The Internet and pet health information: perceptions and behaviors of pet owners and veterinarians. Internet Journal of Veterinary Medicine. 8(1), 19. DOI: https://doi.org/10.5580/26a7

18. Boden, L. (2018). Pet owners turn to the internet for advice: will vets be there to provide an information prescription? Vet Record. British Veterinary Association. 182, 599-600.

DOI: https://doi.org/10.1136/vr.k2146

19. Hofmeister, E.H., Watson, V., Snyder, L.B.C. and Love, E.J. (2008). Validity and client use of information from the World Wide Web regarding veterinary anesthesia in dogs. Journal of the American Veterinary Medical Association. 233(12), 1860-4. DOI: https://doi.org/10.2460/javma.233.12.1860

20. Kogan, L., Oxley, J. A., Hellyer, P., Schoenfeld, R., and Rishniw, M. (2018). UK pet owners' use of the internet for online pet health information. Vet Record. British Veterinary Association. 182(21), 601. DOI: https://doi.org/10.1136/vr.104716 
21. Bao, Y., Hoque, R. and Wang, S. (2017). Investigating the determinants of Chinese adult children's intention to use online health information for their aged parents. International Journal of Medical Informatics. 102, 12-20. DOI: https://doi.org/10.1016/j.ijmedinf.2017.01.003

22. Bergström, A.L. and Hanson, E. (2018). An integrative review of information and communication technology based support interventions for carers of home dwelling older people. Technology and Disability. 29(1-2), 1-14. DOI: https://doi.org/10.3233/tad-160158

23. Chiu, Y.C. (2011). Probing, impelling, but not offending doctors: the role of the internet as an information source for patients' interactions with doctors. Quality Health Ressearch. 21(12), 1658-66. DOI: https://doi.org/10.1177/1049732311417455

24. Eysenbach, G. and Diepgen, T.L. (1999). Patients Looking for Information on the internet and Seeking Teleadvice. Arch Dermatol. 135(2), 151-6. DOI: https://doi.org/10.1001/archderm.135.2.151

25. Kłak, A., Gawińska, E., Samoliński, B. and Raciborski, F. (2017). Dr Google as the source of health information - the results of pilot qualitative study. Polish Annals of Medicine. 24(2), 188-93. DOI: https://doi.org/10.1016/i.poamed.2017.02.002

26. Lee, K., Hoti, K., Hughes, J.D. and Emmerton, L. (2014). Dr Google and the consumer: a qualitative study exploring the navigational needs and online health information-seeking behaviors of consumers with chronic health conditions. Journal of Medical Internet Research. 16(12), 262.

DOI: https://doi.org/10.2196/imir.3706

27. Malone, M., While, A. and Roberts, J. (2014). Parental health information seeking and re-exploration of the 'digital divide.' Primary Health Care Research and Development. 15(2),202-12. DOI: https://doi.org/10.1017/s1463423613000194

28. Manganello, J.A., Falisi, A.L., Roberts, K.J., Smith, K.C. and Mckenzie, L.B. (2016). Pediatric injury information seeking for mothers with young children: the role of health literacy and ehealth literacy. Journal of Communication Healthcare. 9(3), 223-231.

DOI: https://doi.org/10.1080/17538068.2016.1192757

29. Shroff, P.L., Hayes, R.W., Padmanabhan, P. and Stevenson, M.D. (2017). Internet usage by parents prior to seeking care at a pediatric emergency department: observational study. Interactive Journal of Medical Research. 6(2), e17. DOI: https://doi.org/10.2196/ijmr.5075

30. Kim, G.R. and Lehmann, C.U. (2003). The impact of the internet on pediatric medicine. Pediatric Drugs. 5, 433-41. DOI: https://doi.org/10.2165/00128072-200305070-00001

31. Stevenson, F.A., Kerr, C., Murray, E. and Nazareth, I. (2007). Information from the internet and the doctor-patient relationship: the patient perspective - a qualitative study. BMC Family Practice. 8(1), 47. DOI: https://doi.org/10.1186/1471-2296-8-47

32. Tan, S-S.L. and Goonawardene, N. (2017). Internet health information seeking and the patientphysician relationship: A systematic review. Journal of Medical Internet Research. 19(1), e9. DOI: https://doi.org/10.2196/jmir.5729

33. Pilgram, M. (2009). The Dilemma of Offering Social Support: The Veterinarians' View. Death Studies. 28(2), 97-105. DOI: https://doi.org/10.1080/07481181003761666

34. Cornell, K.K. and Kopcha, M. (2007). Client-Veterinarian Communication: Skills for Client Centered Dialogue and Shared Decision Making. Veterinary Clinics of North America: Small Animal Practice. 37(1), 37-47. DOI: https://doi.org/10.1016/i.cvsm.2006.10.005

35. Frankel, R.M. (2006). Communication: An Essential Veterinary Professional Attribute Pets, Vets, and Frets: What Relationship-Centered Care Research Has to Offer Veterinary Medicine. Journal of Veterinary Medical Education. 33(1), 20-7. DOI: https://doi.org/10.3138/jvme.33.1.20

36. Mellanby, R.J., Rhind, S.M., Bell, C., Shaw, D.J., Gifford, J., Fennell, D., Manser, C., Spratt, D.P., Wright, M.J., Zago, S. and Hudson, N.P. (2011). Perceptions of clients and veterinarians on what attributes constitute "A good vet." Vet Record. 168(23), 616. DOI: https://doi.org/10.1136/vr.d925

37. Robinson, O.C. (2014). Sampling in Interview-Based Qualitative Research: A Theoretical and Practical Guide. Qualative Research in Psychology. 11(1), 25-41.

DOI: https://doi.org/10.1080/14780887.2013.801543 
38. Lue, T., Pantenburg, D. and Crawford, P. (2008). Impact of the owner-pet and client-veterinarian bond on the care that pets receives. Journal of the American Veterinary Medical Association. 232(4), 531-40. DOI: https://doi.org/10.2460/javma.232.4.531

39. Ness, P. and Fusch, L. (2015). Are We There Yet? Data Saturation in Qualitative Research. The Qualitative Report. 20(9), 1409-16.

40. Creswell, J.W. and Miller, D.L. (2004). Determining Validity in Qualitative Inquiry. Theory Into Practice. 39(3), 124-30. DOI: https://doi.org/10.1207/s15430421tip3903 2

41. Braun, V. and Clarke, V. (2006). Using thematic analysis in psychology. Qualitative Research in Psychology. 3(2), 77-101. DOI: https://doi.org/10.1191/1478088706qp063oa

42. Kogan, L., Goldwaser, G., Stewart, S.M. and Schoenfeld-Tacher, R. (2008). Sources and frequency of use of pet health information and level of confidence in information accuracy, as reported by owners visiting small animal veterinary practices. Journal of the American Veterinary Medical Association. 232(10), 1536-42. DOI: https://doi.org/10.2460/javma.232.10.1536

43. Kogan, L., Schoenfeld-Tacher, R., Gould, L., Viera, A. and Hellyer, P. (2014). Providing an information prescription in veterinary medical clinics: a pilot study. Journal of the Medical Library Association. 102(1), 41-6. DOI: https://doi.org/10.3163/1536-5050.102.1.008

44. Bell, R.A., Hu, X., Orrange, S.E. and Kravitz, R.L. (2011). Lingering questions and doubts: online information-seeking of support forum members following their medical visits. Patient Education and Counseling. 85(3), 525-8. DOI: https://doi.org/10.1016/j.pec.2011.01.015

45. Usher, W.T. (2011). Australian health professionals' health website recommendation trends. Health Promot Journal of Australia. 22(2), 134-41. DOI: https://doi.org/10.1071/he11134

46. Usher, W.T. (2007). Gold coast general practitioners' recommendations of health websites to their patients. Medical Journal of Australia. 187(2), 82-3. DOI: https://doi.org/10.5694/i.13265377.2007.tb01145.x

47. Tan, SS-LL. and Goonawardene, N. (2017). Internet health information seeking and the patientphysician relationship: a systematic review. Journal of Medical Internet Research. 19(1), 9. DOI: https://doi.org/10.2196/imir.5729

48. Mota, L.R.A da., Ferreira, C.C.G., Costa Neto, H.A.A da, Falbo, A.R. and Lorena, S. de B. (2018). Is doctor-patient relationship influenced by health online information? Revista da Associação Médica Brasileira. 64(8), 692-9. DOI: https://doi.org/10.1590/1806-9282.64.08.692

49. Crooks, V.A. (2006). "I go on the internet; I always, you know, check to see what's new": Chronically III women's use of online health information to shape and inform doctor-patient interactions in the space of care provision. Acme. 5(1), 50-69.

50. Bowes, P., Stevenson, F., Ahluwalia, S. and Murray, E. (2012). "I need her to be a doctor": patients' experiences of presenting health information from the internet in GP consultations. British Journal of General Practice. 62, 732-8. DOI: https://doi.org/10.3399/bjgp12×658250

51. Bylund, C.L., Gueguen, J.A., D'Agostino, T.A., Li, Y. and Sonet, E. (2010). Doctor-patient communication about cancer-related internet information. Journal of Psychosocial Oncology. 28(2), 127-42.

DOI: https://doi.org/10.1080/07347330903570495

52. Bylund, C.L., Gueguen, J.A., Sabee, C.M., Imes, R.S., Li, Y. and Sanford, A.A. (2007). Provider-patient dialogue about internet health information: An exploration of strategies to improve the providerpatient relationship. Patient Education and Counseling. 66(3), 346-52. DOI: https://doi.org/10.1016/j.pec.2007.01.009

53. Wang, J., Ashvetiya, T., Quaye, E., Parakh, K. and Martin, S.S. (2018). Online health searches and their perceived effects on patients and patient-clinician relationships: a systematic review. The American Journal of Medicine. 131(10), 1250.e1-1250.e10. DOI: https://doi.org/10.1016/j.amjmed.2018.04.019

54. Murray, E., Lo, B., Pollack, L., Donelan, K., Catania, J., Lee, K., Zapert, K. and Turner, R. (2003). The impact of health information on the internet on health care and the physician-patient relationship: national U.S. survey among 1.050 U.S. physicians. Journal of Medical Internet Research. 5(3), e17. DOI: https://doi.org/10.2196/imir.5.3.e17 
55. Schrank, B., Sibitz, I., Unger, A. and Amering, M.. (2010). How patients with schizophrenia use the internet: qualitative study. Journal of Medical Internet Research. 12(5).

DOI: https://doi.org/10.2196/jmir.1550

56. Tischler, V.A., Cobb, M.A., Dean, R.S., Robbé, I.J., McDermott, M.P. (2015). Veterinarian-client communication skills: current state, relevance, and opportunities for improvement. Journal of Veterinary Medical Education. 42(4), 305-14. DOI: https://doi.org/10.3138/jvme.0115-006r

57. Hamood, W.J., Chur-Hansen, A. and McArthur, M.L. (2014). A qualitative study to explore communication skills in veterinary medical education. International Journal of Medical Education. 5 , 193-8. DOI: https://doi.org/10.5116/ijme.542a.975d

58. Van Riel, N., Auwerx, K., Debbaut, P., Van Hees, S. and Schoenmakers, B. (2017). The effect of Dr Google on doctor-patient encounters in primary care: a quantitative, observational, cross-sectional study. BJGP Open. 1(2), BJGP-2017-0833. DOI: https://doi.org/10.3399/bigpopen17x100833

59. Chen, Y.Y., Li, C.M., Liang, J.C. and Tsai, C.C. (2018). Health information obtained from the internet and changes in medical decision making: Questionnaire development and cross-sectional survey. Journal of Medical Internet Research. 20(2). DOI: https://doi.org/10.2196/imir.9370

60. Topaz, M., Bar-Bachar, O., Admi, H., Denekamp, Y. and Zimlichman, E. (2019). Patient-centered care via health information technology: a qualitative study with experts from Israel and the U.S. Informatics for Health and Social Care. DOI: https://doi.org/10.1080/17538157.2019.1582055

61. Woodward-Kron, R., Connor, M., Schulz, P.J. and Elliott, K. (2014). Educating the patient for health care communication in the age of the World Wide Web: a qualitative study. Academic Medicine. 89(2), 318-25. DOI: https://doi.org/10.1097/acm.0000000000000101 


\section{EVIIDEveE \\ brought to you by \\ RCVS KNOWLEDGE}

\section{Intellectual Property Rights}

Authors of Knowledge Summaries submitted to RCVS Knowledge for publication will retain copyright in their work, and will be required to grant RCVS Knowledge a non-exclusive license of the rights of copyright in the materials including but not limited to the right to publish, re-

publish, transmit, sell, distribute and otherwise use the materials in all languages and all media throughout the world, and to license or permit others to do so.

\section{Disclaimer}

Any opinions expressed in articles and other publication types published in Veterinary Evidence are the author's own and

do not necessarily reflect the view of the RCVS Knowledge. Veterinary Evidence is a resource to help inform, and the content herein should not override the responsibility of the practitioner. Practitioners should also consider factors such as individual clinical expertise and judgement along with patient's circumstances and owners' values. Authors are responsible for the accuracy of the content. While the Editor and Publisher believe that all content herein are in accord with current recommendations and practice at the time of publication, they accept no legal responsibility for any errors or omissions, and make no warranty, express or implied, with respect to material contained within.

For further information please refer to our Terms of Use.

RCVS Knowledge is the independent charity associated with the Royal College of Veterinary Surgeons (RCVS). Our ambition is to become a global intermediary for evidence based veterinary knowledge by providing access to information

that is of immediate value to practicing veterinary professionals and directly contributes to evidence based clinical decision-making.

\section{https://www.veterinaryevidence.org/}

RCVS Knowledge is a registered Charity No. 230886.

Registered as a Company limited by guarantee in England and Wales No. 598443.

Registered Office: Belgravia House, 62-64 Horseferry Road, London SW1P 2AF

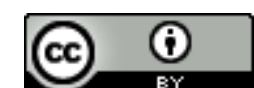

This work is licensed under a Creative Commons Attribution 4.0 International License. 